\title{
Evaluation of Selected Nonfumigant Nematicides on Increasing Inoculation Densities of Meloidogyne incognita on Cucumber
}

\author{
Abolfazl Hajihassani, ${ }^{1, \dagger}$ Richard F. Davis, ${ }^{2}$ and Patricia Timper, ${ }^{2}$ \\ ${ }^{1}$ Department of Plant Pathology, University of Georgia, Tifton, GA 31793 \\ ${ }^{2}$ Crop Protection and Management Research Unit, USDA ARS, Tifton, GA 31793
}

\begin{abstract}
The southern root-knot nematode (RKN), Meloidogyne incognita, is particularly difficult to manage because of high susceptibility of all commercial cucumber (Cucumis sativus) cultivars to this nematode. Growers have conventionally relied on nematicide applications to control RKN. Two microplot experiments were conducted in which four nonfumigant nematicides, oxamyl, fluopyram, fluensulfone, and fluazaindolizine, were examined for their efficacy in reducing gall severity and postharvest soil nematode numbers in microplots inoculated with increasing inoculation densities $(1,000,5,000,10,000$, and 20,000 nematodes/microplot), and improving growth and yield of cucumber. Nematicides were applied 1 day prior to transplanting cucumber seedlings, except fluensulfone, which was applied 7 days before transplanting. At harvest, root gall in-

the root gall index when compared with the untreated control on a consistent basis at all $M$. incognita inoculation densities. At the lowest inoculation density, no significant difference in gall index or final population density was observed among nematicides; however, gall index increased with increasing nematode inoculation densities in nematicide-treated microplots. Correlations between gall index and inoculation density clearly showed that soil treatment with fluensulfone, fluazaindolizine, or fluopyram was more effective in reducing gall severity than treatment with oxamyl. Regression analysis also indicated no significant effect of nematode inoculation densities on yield of cucumber treated with these nematicides. Results of this study will provide guidance for improving nematicide efficiencies in soil with varying inoculation densities of RKN
\end{abstract} dices differed significantly $(P<0.0001)$ among nematode inoculation densities and nematicides. All four nematicides were effective in reducing
Keywords: cucumber, Meloidogyne incognita, nonfumigant nematicides
Cucumber (Cucumis sativus L.) is the fifth most important vegetable crop grown in Georgia. The majority of cucumbers are grown in monocrop, double-crop, or multiple-crop systems in the southern part of the state from May through October for fresh market consumption. Georgia growers produced approximately 3,311 hectares of cucumber with the farm gate value accounting for more than $\$ 78$ million in 2017 (Wolfe and Stubbs 2018). The southern rootknot nematode (RKN; Meloidogyne incognita (Kofoid \& White) Chitwood) is the most important yield-limiting plant-parasitic nematode, affecting all vegetable crops including cucumber production in the southeastern United States (Davis 2007; Hajihassani et al. 2018; Johnson et al. 1981; Thies et al. 2016). Light textured (sandy) soils in Georgia are commonly infested with RKN, and cucumber yield reduction can be very high even with low inoculation densities. Reducing the risk of yield losses due to Meloidogyne spp. is a year-round concern for growers in vegetable producing systems with nematode densities increasing at the end of the growing season (Hajihassani et al. 2019).

Major current management methods to control RKN in vegetable crops include soil fumigation prior to planting, application of nonfumigant nematicides prior to planting, at- and post-planting, and using resistant cultivars. A source of resistance to $M$. incognita has not been identified in germplasm accessions of $C$. sativus (Walters and Wehner 2002), and no commercial cucumber cultivars with resistance to the nematode are currently available. In this context, effective management of RKN relies greatly on individual or combined applications of fumigant and nonfumigant nematicides (Desaeger and

${ }^{\dagger}$ Corresponding author: A. Hajihassani; abolfazl.hajihassani@uga.edu

Funding: This research was supported by the Georgia Fruit and Vegetable Growers Association.

The author(s) declare no conflict of interest.

Accepted for publication 28 May 2019.

C 2019 The American Phytopathological Society
Csinos 2006; Morris et al. 2015). However, application of fumigant products requires specialized injection equipment by contract operators, leading to higher production costs. In addition, fumigants are extremely toxic to human and nontarget soil organisms (Zasada et al. 2010).

Oxamyl (trade name: Vydate; Corteva Agriscience) has been on the market for decades, and several new nonfumigant active ingredients have recently been registered in the United States for RKN management in vegetable crops. These new products include fluopyram (trade name: Velum Prime; Bayer CropScience, Inc.) and fluensulfone (trade name: Nimitz; ADAMA Agricultural Solutions), which have received attention due to their good nematicidal activity and low toxicity to nontarget organisms and the environment (Hajihassani 2018; Morris et al. 2015). In addition, a nonregistered nematicide, fluazaindolizine (trade name: Salibro; Corteva Agriscience), has been shown to provide RKN control on some crops such as tomato and corn (da Rocha et al. 2017; A. Hajihassani and B. H. Luke, unpublished).

According to the manufacture's label of registered nonfumigant nematicides, a single rate is recommended for use across a field in spite of varying inoculation densities of RKN present in soil. Application of a single rate might not provide a sufficient amount of root protection against high densities of RKN. This is due to the fact that nematicides differ in their effectiveness depending on their activity in soil, sensitivity of the nematode species to the product, population density of the nematode in soil, application method (e.g., drip chemigation, foliar or in-furrow application), and environmental factors (e.g., soil texture, soil temperature and moisture) (Brodie 1971; Johnson et al. 1981; Oka et al. 2012, 2013; Vrain et al. 1979). All these factors might influence nematicide efficacy as well as nematode development and reproduction.

Relationships between inoculation densities of RKN and vegetable yields have been evaluated extensively, and a direct correlation between a population increase of the nematode and subsequent reduction in yield has been reported (Barker et al. 1976; Di Vito et al. 1986; Olthof and Potter 1972). Understanding the relationship of varying inoculation densities of RKN to nematicides could lead to more efficient use of nematicides to maximize nematode control with minimum cost. This information is particularly important to 
determine which nematicide(s) within treatment programs will be most effective in soil with low, medium, or high infestation of nematodes. Therefore, this study was conducted to assess the efficacy of selected conventional and newly introduced nonfumigant nematicides in microplots infested with different inoculation densities of $M$. incognita on the nematode reproduction and the growth and yield of cucumber.

\section{Materials and Methods}

Preparation of nematode inoculum. A known population of $M$. incognita race 3 (Hajihassani et al. 2019) was increased on eggplant (Solanum melongena) 'Purple Shine Hybrid' in the greenhouse. Plants were inoculated with 3,000 nematodes and grown for 100 days in 3-liter polyethylene pots filled with pasteurized field soil. Afterward, the plants were uprooted, and the infected roots were chopped into small fragments and placed on a screen on top of a stainless steel collection pot. The pot was placed in a mist chamber for 7 days, after which the collected water was passed through nested 149- and 25- $\mu$ m-pore sieves. Fresh second-stage juveniles (J2) remaining on the 25 - $\mu \mathrm{m}$-pore sieve were enumerated under an inverted microscope (Leica DM IL, Germany). The nematode suspension was adjusted with tap water to $5,000 \mathrm{~J} 2 / \mathrm{ml}$ water, and then refrigerated at $5^{\circ} \mathrm{C}$ until use within 2 to 3 days after recovery.

Infestation of microplots. An experiment was initiated on 24 April 2018 and repeated beginning 28 July 2018. Each treatment (nematode inoculation density and untreated control) had five replicates arranged in randomized complete block design. Experiments were conducted in cylindrical ( $76 \mathrm{~cm}$ diameter) bottomless stainless steel drums extending $53 \mathrm{~cm}$ below and $10 \mathrm{~cm}$ above the soil surface filled with a sandy loam soil ( $86 \%$ sand, $7 \%$ clay, and $7 \%$ silt) located at the University of Georgia, Tifton Campus, GA. Three weeks prior to nematode inoculation, all the microplots were fumigated with metam sodium (trade name: Vapam; AMVAC Chemical Corporation) to disinfest the soil. Each microplot was soil drenched with $100 \mathrm{ml}$ a.i. of metam sodium mixed with 30 liters of water in a bucket. The microplots were then left uncovered for 3 weeks, allowing the toxic active ingredient residues to dissipate. Microplots were watered lightly and then four holes 20 -cm-deep and 1-cm-wide were made using a plastic graduated pipette spaced equidistantly and approximately $8 \mathrm{~cm}$ from the center and $30 \mathrm{~cm}$ from the edge of the plots. Four inoculation densities of 1,000, 5,000, 10,000, or 20,000 M. incognita $\mathrm{J} 2 /$ microplot were pipetted into the holes. The soil surrounding the holes in the center of each microplot was thoroughly mixed with a garden shovel.

Application of nematicides and planting cucumber. Nonfumigant nematicides were injected into the soil using watering spikes $(13.5 \times 2.7 \times 2.7 \mathrm{~cm})($ Outus 8 Pieces Automatic Control Drip Plant Watering Spikes) which were screwed onto 1-liter drink bottles to simulate drip application. Two drainage holes were pierced with a pushpin 2.5 and $5 \mathrm{~cm}$ from the nozzle tip on opposite sides of each spike. The bottles were filled with 1 liter of tap water to which were added: oxamyl at 4.67 liter a.i./ha, fluopyram at 0.50 liter a.i./ha, fluensulfone at 5.84 liter a.i./ha, or fluazaindolizine at 4.48 liter a.i./ha. All nematicides were applied at their maximum recommended rates and application times as per the product label for vegetable crops. Nematicides were applied 1 day prior to transplant, except fluensulfone, which was applied 7 days before transplanting.

The spikes were screwed onto the bottles and inserted into the soil approximately $2 \mathrm{~cm}$ above the second hole made in the spike. Then the soil surface around the spike was compacted by hand to make the bottles stable. The nematicides completely drained from the bottles within 6 to $12 \mathrm{~h}$ because of hydrostatic pressure. Microplots infested with the same four inoculation densities of $M$. incognita and treated with water served as untreated controls.

Seeds of cucumber 'Mongoose' were grown in 128-cell plug trays (Speedling Incorporated, Ruskin, FL) filled with Promix HP Mycorrhizae potting mix (ProMix, Québec, Canada). A single 15-day-old seedling was transplanted in the center of each microplot approximately $2 \mathrm{~cm}$ deeper than the soil surface on 24 April 2018 in the first trial and on 28 July 2018 in the repeat trial. All microplots were irrigated uniformly by hand when cucumber seedlings were transplanted and as needed thereafter. Before planting, soil from the microplots was tested for nutrient content and fertilized with $\mathrm{N}, \mathrm{P}$, and $\mathrm{K}$ according to soil nutrient analysis. Fertilizer (Agrium, Loveland, $\mathrm{CO}$ ) was applied to the microplots at $16.25 \mathrm{~kg} / \mathrm{ha}$ as $5-10-15$ (N-P-K) postplanting and 2 and 4 weeks after transplanting at $8.12 \mathrm{~kg} / \mathrm{ha}$ as 10-10-10 (N-P-K). In the first experiment, limestone was added to the microplots at $1,120 \mathrm{~kg} / \mathrm{ha}$. In both trials, weeds were controlled by hand and recommended disease management practices according to Georgia Pest Management Handbook were used across the microplots. Foliar spray of the fungicide Orondis Opti A (a.i. oxathiapiprolin; Syngenta) at 0.29 liter a.i./ha was applied for control of downy mildew two to four times in each experiment as needed. Two foliar applications of the insecticide Sivanto Prime (a.i. flupyradifurone; Bayer CropScience) at the rate of 0.76 liter a.i./ha were used for control of whiteflies.

Data collection. Maximum and minimum air temperatures were recorded. Mean temperatures for the first and second trials were $25.1^{\circ} \mathrm{C}$ (range of 10.0 to $35.2^{\circ} \mathrm{C}$ ) and $27.3^{\circ} \mathrm{C}$ (range of 20.2 to $35.3^{\circ} \mathrm{C}$ ), respectively. Five days after transplanting, phytotoxicity ratings from each microplot were collected. Plant vigor was rated at midseason (30 days after nematicide application), and gall index was recorded 60 days after planting. Phytotoxicity was rated using a $0-5$ scale, where $0=$ no phytotoxicity, and $5=100 \%$ phytotoxicity. Plant vigor was rated using a $0-5$ scale, where $0=$ dead plant, and $5=$ best growth. Each plant was uprooted, immersed and washed thoroughly in tap water, and indexed for severity of root galling. Gall index was rated using a $0-5$ scale, where $0=$ no galls, $1=$ trace of nematode with few galls on roots, $2=\leq 25 \%$ root galling, $3=26$ to $50 \%, 4=51$ to $75 \%, 5=76$ to $100 \%$ galling (Hussey and Janssen 2002). At harvest, soil samples for nematode counts were obtained by collecting three cores with a 2.5 -cm-diameter soil probe at a depth of 15 to $20 \mathrm{~cm}$ in the center of each microplot. Nematode $\mathbf{J} 2$ were extracted from a $100-\mathrm{cm}^{3}$ subsample of soil from each microplot by the sugar-flotation-sieving method (Jenkins 1964) and counted. Cucumber fruits were harvested by hand on a weekly basis during the experiment, and total yield for each treatment was recorded at the termination of the experiment.

Statistical analyses. Data were analyzed using PROC MIXED model in SAS software (v. 9.4; SAS Institute Inc., Cary, NC), where nematode inoculation density and nematicides were considered a fixed effect, whereas trial number was considered a random effect. Data for two trials were pooled since no significant difference was observed $(P<0.791)$ between means of repeat trials. Least square means (LS-means) comparisons were performed using the Tukey's honest significance difference test $(\alpha=0.05)$, and means were portioned using the slice command. Data were subjected to regression analysis to determine the significance of the relationship of root gall index and crop yield (dependent variables) to inoculation densities (independent variables) of the nematode in microplots with and without nematicide application. Differences in parameter estimates for the slopes among nematicide treatments for gall index and final population density of the nematode (Glantz and Slinker 2001) were conducted using the REG procedure in SAS.

\section{Results}

In microplots that were inoculated with 5,000 and 10,000 M. incognita, phytotoxicity was slightly greater on cucumber plants treated with fluopyram compared with other nematicides, except fluazaindolizine at the 5,000 inoculation density (Table 1). Fortyone days after transplanting, the plants showed slight yellowing symptoms in the microplots infested with $M$. incognita but not treated with nematicides, while the plants in all nematicide-treated microplots were growing normally. In microplots that were inoculated with 10,000 and 20,000 nematodes, the plant vigor was $(P<0.05)$ increased from the untreated control using fluopyram and fluazaindolizine (Table 1). For the root gall index and final population density of $M$. incognita, the main effects of nematicide, inoculation density, and the interactive effect of nematicide $\times$ inoculation density were 
significant $(P<0.0001)$. An interaction between nematicide and inoculation density indicated that efficacy of the nematicides varied among nematode inoculation densities. Thus, efficacy among the four nematicides was compared separately for each of the inoculation densities (Figs. 1 and 2).

At harvest, root gall index and final population of the nematode was lower $(P<0.05)$ in all nematicide-treated microplots than in the untreated control (Figs. 1 and 2). There was no significant difference among nematicides at the lowest inoculation density (1,000 J2); however, root gall index increased with increasing inoculation densities of $M$. incognita in microplots with and without nematicide treatment (Fig. 1). At the inoculation densities of 5,000, 10,000, and 20,000, the efficacy of fluopyram, fluazaindolizine, and fluensulfone in reducing the gall indices was $(P<0.05)$ greater compared with the oxamyl treatment (Fig. 1). At the 5,000 inoculation density, efficacy in reducing final population density by fluopyram, fluazaindolizine, and fluensulfone were equal to or greater than that of oxamyl. In microplots inoculated with 10,000 and 20,000 nematodes and receiving fluazaindolizine or fluensulfone, final population densities were significantly lower than that in microplots with oxamyl or fluopyram treatment (Fig. 2).

The percent reduction in gall severity and final populations of the nematode in microplots treated with nematicides are shown in Table 2. Depending upon the inoculation density and compared with the untreated control, the application of oxamyl, fluopyram, fluazaindolizine, and fluensulfone resulted in root gall index reductions of 76, 79,81 , and $83 \%$, respectively, at the lowest inoculation density $(1,000 \mathrm{~J} 2)$ and by $36,60,72$, and $78 \%$, respectively, at the greatest

Table 1. Effects of nonfumigant nematicides on phytotoxicity, vigor, and yield of cucumber grown in outdoor microplots infested with four inoculation densities of Meloidogyne incognita

\begin{tabular}{|c|c|c|c|c|}
\hline $\begin{array}{l}\text { Inoculation } \\
\text { density/ } \\
\text { microplot }\end{array}$ & Nematicide & Phytotoxicity $^{y}$ & $\begin{array}{l}\text { Plant } \\
\text { vigor }^{y}\end{array}$ & $\begin{array}{l}\text { Yield }(\mathrm{kg} / \\
\text { microplot) }\end{array}$ \\
\hline \multicolumn{5}{|l|}{1,000} \\
\hline & Untreated & $\ldots$ & $3.0 \mathrm{a}^{\mathrm{z}}$ & $2.6 \mathrm{~b}$ \\
\hline & Oxamyl & $0.2 \mathrm{a}$ & $3.0 \mathrm{a}$ & $2.6 \mathrm{~b}$ \\
\hline & Fluopyram & $0.5 \mathrm{a}$ & $3.4 \mathrm{a}$ & $3.8 \mathrm{a}$ \\
\hline & Fluazaindolizine & $0.3 \mathrm{a}$ & $3.1 \mathrm{a}$ & $3.2 \mathrm{ab}$ \\
\hline & Fluensulfone & $0.2 \mathrm{a}$ & $3.8 \mathrm{a}$ & $3.4 \mathrm{ab}$ \\
\hline \multicolumn{5}{|l|}{5,000} \\
\hline & Untreated & $\ldots$ & $3.3 \mathrm{a}$ & $2.4 \mathrm{~b}$ \\
\hline & Oxamyl & $0.2 \mathrm{~b}$ & $3.8 \mathrm{a}$ & $3.1 \mathrm{ab}$ \\
\hline & Fluopyram & $0.6 \mathrm{a}$ & $4.2 \mathrm{a}$ & $3.7 \mathrm{a}$ \\
\hline & Fluazaindolizine & $0.4 \mathrm{a}$ & $3.7 \mathrm{a}$ & $3.4 \mathrm{ab}$ \\
\hline & Fluensulfone & $0.3 \mathrm{~b}$ & $3.6 \mathrm{a}$ & $3.2 \mathrm{ab}$ \\
\hline \multicolumn{5}{|l|}{10,000} \\
\hline & Untreated & $\ldots$ & $2.8 \mathrm{~b}$ & $2.1 \mathrm{~b}$ \\
\hline & Oxamyl & $0.4 \mathrm{a}$ & $3.6 \mathrm{ab}$ & $2.9 \mathrm{ab}$ \\
\hline & Fluopyram & $0.8 \mathrm{~b}$ & $4.0 \mathrm{a}$ & $3.5 \mathrm{a}$ \\
\hline & Fluazaindolizine & $0.3 \mathrm{a}$ & $3.2 \mathrm{ab}$ & $3.3 \mathrm{a}$ \\
\hline & Fluensulfone & $0.2 \mathrm{a}$ & $3.7 \mathrm{ab}$ & $3.5 \mathrm{a}$ \\
\hline \multicolumn{5}{|l|}{20,000} \\
\hline & Untreated & $\ldots$ & $2.6 \mathrm{~b}$ & $2.0 \mathrm{~b}$ \\
\hline & Oxamyl & $0.3 \mathrm{a}$ & $3.3 \mathrm{ab}$ & $2.6 \mathrm{ab}$ \\
\hline & Fluopyram & $0.6 \mathrm{a}$ & $3.6 \mathrm{a}$ & $3.6 \mathrm{a}$ \\
\hline & Fluazaindolizine & $0.2 \mathrm{a}$ & $3.5 \mathrm{a}$ & $3.5 \mathrm{a}$ \\
\hline & Fluensulfone & $0.2 \mathrm{a}$ & $3.4 \mathrm{ab}$ & $3.4 \mathrm{a}$ \\
\hline \multicolumn{5}{|l|}{$P>F$} \\
\hline \multicolumn{2}{|c|}{ Nematicide } & 0.0001 & 0.0057 & 0.0001 \\
\hline \multicolumn{2}{|c|}{ Inoculation density } & 0.8362 & 0.0756 & 0.9216 \\
\hline \multicolumn{2}{|c|}{ Nematicide $\times$ inoculation density } & 0.9063 & 0.7356 & 0.8273 \\
\hline
\end{tabular}

${ }^{y}$ Phytotoxicity and plant vigor were rated (separately) using a $0-5$ scale, where $0=$ no $\%$ phytotoxicity; very poor growth, and $5=100 \%$ phytotoxicity; best growth.

${ }^{\mathrm{z}}$ Data are the means of two trials and means $(n=10)$ of phytotoxicity, plant vigor, or yield followed by the same letter within a nematode inoculation density did not differ significantly at $\alpha=0.05$ as determined by using the slice command in SAS. inoculation density (20,000 J2) (Table 2). Similarly, final population densities of the nematode were reduced as much as $73,73,78$, and $91 \%$, respectively, at the lowest inoculation density and by 64,79 , 91, and $94 \%$ at the greatest inoculation density in microplots treated with oxamyl, fluopyram, fluazaindolizine, and fluensulfone, respectively, compared with the untreated control. The regression analyses indicated differences among nematicides across inoculation densities. There was a positive correlation between either root gall index $\left(r^{2}=0.2\right)$ or final population density $\left(r^{2}=0.4\right)$ with $M$. incognita inoculation densities in microplots with no nematicide treatments (Figs. 3 and 4). The regression line for fluazaindolizine and fluensulfone had a slope of zero. Thus, these nematicides performed similarly at different inoculation densities in reducing gall severity and final population density of the nematode (Figs. 3 and 4). Regression lines for oxamyl and fluopyram had positive slopes, indicating that the efficacy of these nematicides decreased with increasing inoculation densities of $M$. incognita (Figs. 3 and 4). In regression analysis, the parameter estimates (i.e., gall index and final population density) for fluazaindolizine, fluensulfone, and fluopyram were significantly different from those for the regressions of oxamyl (Figs. 3 and 4).

Nematicide treatments did not have a significant influence on crop yield compared with the untreated control for most inoculation densities of $M$. incognita. Among all nematicides examined, fluopyram provided an increase in cucumber yield at all four inoculation densities compared with untreated control (Table 1). Treatments of fluazaindolizine and fluensulfone were more $(P<0.05)$ effective in increasing cucumber yield compared with the untreated control at 10,000 and 20,000 inoculation densities (Table 1).

The percent increase in crop yield in microplots treated with nematicides are shown in Table 2. The application of oxamyl, fluopyram,

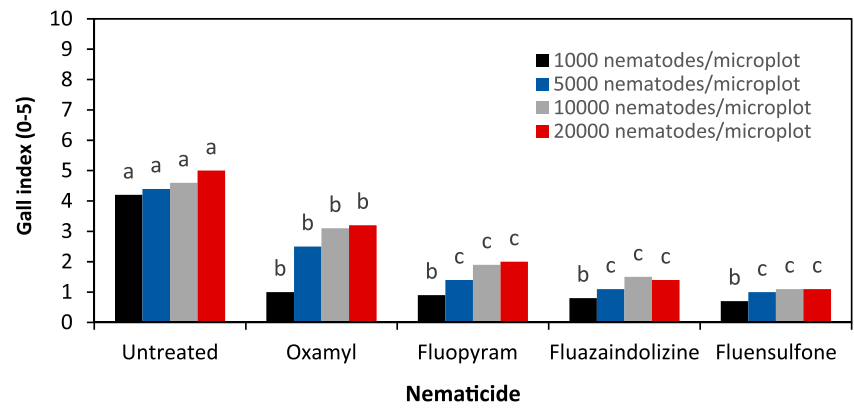

Fig. 1. Effect of soil treatment with four nonfumigant nematicides on root gall index of cucumber inoculated with four inoculation densities of Meloidogyne incognita in microplots under field conditions. Bars signify the mean values of 10 replicates per treatment combined from two trials. Bars of the same shade (inoculation density) with the same letter do not differ at $P<0.05$ using Tukey's honest significance difference test to separate means in SAS. Gall index was rated using a $0-5$ scale, where $0=$ no galls, and $5=76$ to $100 \%$ galling of roots.

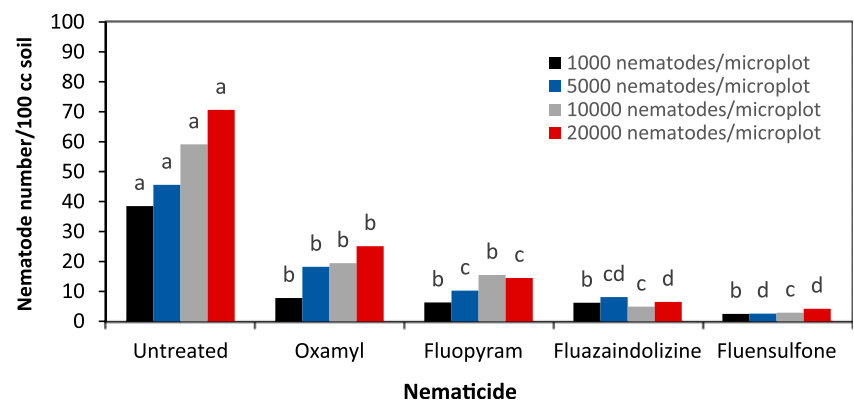

Fig. 2. Effect of soil treatment with four nonfumigant nematicides on the number of Meloidogyne incognita at harvest in microplots inoculated with four inoculation densities. Bars signify the mean values of 10 replicates per treatment combined from two trials. Bars of the same shade (inoculation density) with the same letter do not differ at $P<0.05$ using Tukey's honest significance difference test to separate means in SAS. 
fluazaindolizine, or fluensulfone, as compared with the untreated control, resulted in increased yield by $0,46,23$, and $31 \%$, respectively, at the lowest inoculation density and by $30,80,75$, and $70 \%$, respectively, at the greatest inoculation density (Table 2). Regression analyses showed no relationship between increasing inoculation densities of the nematode and yield of cucumber treated with oxamyl $(P<0.82)$, fluopyram $(P<0.28)$, fluazaindolizine $(P<$ $0.58)$, or fluensulfone $(P<0.74)$ (data not shown).

\section{Discussion}

There are no commercially available cucumber cultivars resistant to RKN. Without genetic resistance, all cucumber produced in the United States is vulnerable to RKN and may require the use of nematicide applications for nematode management. Soil-application of nonfumigant nematicides has been commonly used for the production of vegetable crops, and this approach has been shown to be economically

Table 2. Percent reduction of root gall index and final nematode population, and percent increase of cucumber yield, when compared with the untreated control in microplots infested with different inoculation densities of Meloidogyne incognita and treated with nonfumigant nematicides. Data are the means of two trials.

\begin{tabular}{llccc}
\hline \multirow{2}{*}{$\begin{array}{l}\text { Inoculation } \\
\text { density/ } \\
\text { microplot }\end{array}$} & Nematicide & Gall index & $\begin{array}{c}\text { \% Reduction } \\
\text { population } \\
\text { density }\end{array}$ & $\begin{array}{c}\text { Yield } \\
\text { (\% increase) }\end{array}$ \\
\hline 1,000 & & & & \\
& Oxamyl & 76 & 73 & 0 \\
& Fluopyram & 79 & 78 & 46 \\
& Fluazaindolizine & 81 & 78 & 23 \\
5,000 & Fluensulfone & 83 & 91 & 31 \\
& Oxamyl & 43 & 60 & 29 \\
& Fluopyram & 68 & 77 & 58 \\
& Fluazaindolizine & 75 & 82 & 42 \\
10,000 & Fluensulfone & 77 & 94 & 33 \\
& Oxamyl & 33 & 67 & 38 \\
& Fluopyram & 59 & 74 & 67 \\
& Fluazaindolizine & 67 & 92 & 57 \\
\multirow{2}{*}{20,000} & Fluensulfone & 76 & 95 & 67 \\
& & & & \\
& Oxamyl & 36 & 64 & 30 \\
& Fluopyram & 60 & 79 & 80 \\
& Fluazaindolizine & 72 & 91 & 75 \\
& Fluensulfone & 78 & 94 & 70 \\
\hline
\end{tabular}

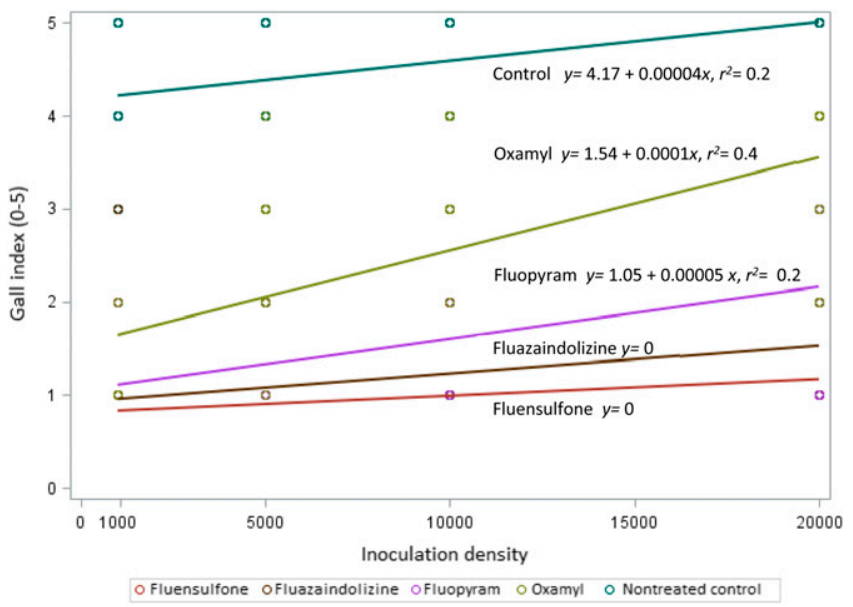

Fig. 3. Relationship between inoculation density $(1,000,5,000,10,000$, and 20,000 nematodes/microplot) of Meloidogyne incognita in soil and root gall index of cucumber treated with oxamyl, fluopyram, fluazaindolizine, and fluensulfone. Data points are means of all replicates $(n=10)$ grouped from two trials. beneficial. Many research studies have assessed the potential of various nonfumigant nematicides against RKN (Desaeger and Csinos 2006; Jones et al. 2017; Morris et al. 2015). However, evaluation of nonfumigant nematicides against different population densities of nematodes can provide additional information on the efficacy of these products that should result in more efficient RKN management. This information is particularly important to know which nematicide(s) within treatment programs will be most effective in soil with low, medium, or high infestation of RKN.

In this study, phytotoxicity symptoms were not observed in plants treated with oxamyl, fluazaindolizine, or fluensulfone. In contrast, fluopyram treatment at the recommended rate produced slight phytotoxicity on cucumber. The phytotoxic effect, however, did not result in poor vigor of plants. Phytotoxicity can result in vegetable crops, usually when the higher rates of nematicides are applied as a soil drench or foliar application. For example, our field experiments have shown that fluopyram as a soil drench at 0.50 liter a.i./ha on cucumber had a phytotoxic effect as compared with the drip application which had no phytotoxicity damage (A. Hajihassani and B. H. Luke, unpublished). Growth-chamber studies have also shown that foliar applications of fluensulfone at $12 \mathrm{~g}$ a.i./liter was phytotoxic to tomato and eggplant (Morris et al. 2016).

Our results indicate that the damage caused by varying inoculation densities of $M$. incognita can be managed effectively with nematicide treatments when applied at recommended rates and times. All nematicides tested significantly reduced gall severity on roots compared with the untreated control on a consistent basis at all inoculation densities tested. However, differences in reducing nematode damage were observed among nematicides at varying inoculation densities of the nematode. In microplots that did not receive nematicides, root galling severity and final population density of the nematode were positively related to $M$. incognita inoculation densities. In contrast, crop yield was inversely related to inoculation densities demonstrating that $M$. incognita negatively influenced yield of cucumber. At the lowest inoculation density of $M$. incognita (1,000 J2/microplot), no significant difference in the gall index or final population densities of the nematode was observed among nematicides. This might suggest that all four nematicides give good control in soil with low pressure from M. incognita.

Oxamyl has been used for decades in controlling plant-parasitic nematodes on various crops (Gugino et al. 2006; Kimpinski et al. 2001; Miller 1971; Morris et al. 2016). In our trials, oxamyl did not provide a high level of root protection and nematode suppression, particularly in the microplots with high nematode pressure $(10,000$ and $20,000 \mathrm{~J} 2 /$ microplot). The high level of gall severity in the oxamyltreated microplots may have been the reason why relatively small differences in cucumber yield were observed between the oxamyl

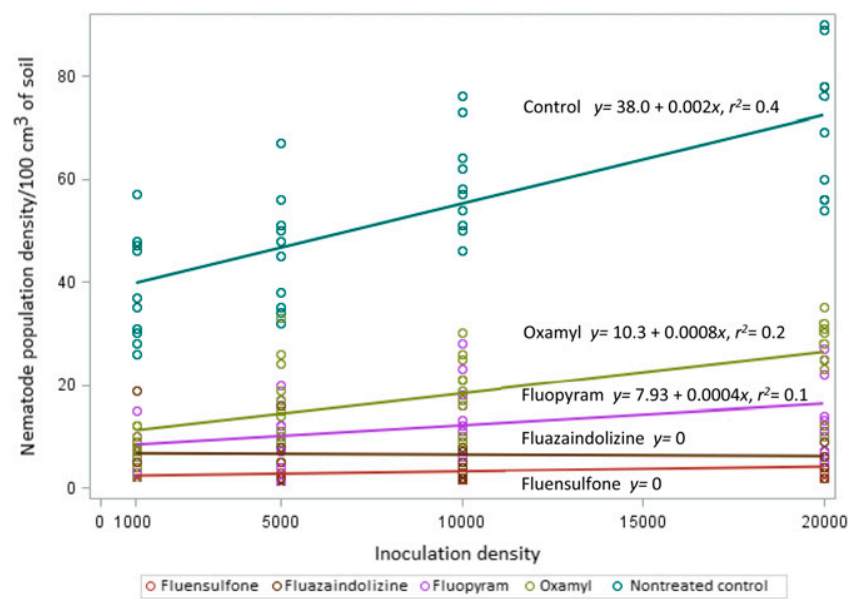

Fig. 4. Relationship between inoculation density $(1,000,5,000,10,000$, and 20,000 nematodes/microplot) and final population density of Meloidogyne incognita in soil treated with oxamyl, fluopyram, fluazaindolizine, and fluensulfone. Data points are means of all replicates $(n=10)$ grouped from two trials. 
treatment and the nontreated control. Although fluopyram reduced gall severity compared with the nontreated control, it did not give protection of cucumber roots in microplots with 10,000 or $20,000 \mathrm{~J} 2 /$ microplot. Fluopyram provided between 46 and $80 \%$ yield increase in cucumber, which was the highest of any nematicide evaluated in this work; perhaps because it contains both nematicidal and fungicidal properties, which may increase its ability to increase yields. The pressure of powdery mildew, a fungal leaf disease, was high in southern Georgia in summer 2018, and our cucumber plants were slightly infected with this disease. As a result, fluopyram, an effective product for the control of powdery mildew (Proffer et al. 2013), may have resulted in higher yield in this study. We found that application of either fluensulfone or fluazaindolizine provided better season-long protection of the root system and reduction in nematode galling on roots than oxamyl or fluopyram. These results are in agreement with those of previous research where fluensulfone gave the greatest reduction in $M$. incognita gall severity and increased yields of tomato or cucumber (Morris et al. 2015) and lima bean (Jones et al. 2017).

In this study, cucumber yields in the nematicide-treated microplots were the same regardless of which nematicide was used, despite a significant reduction in gall severity and nematode number in soil treated with either fluensulfone or fluazaindolizine. This could be due to plants being able to compensate more for RKN damage in microplots where they had no competition from neighboring plants for nutrients and water. RKN control and increased yields of several vegetables such as tomato, pepper, and cucumber (Desaeger and Csinos 2006; Morris et al. 2015) have been achieved when these crops were planted in soil treated with fluensulfone. Fluazaindolizine, which is not currently registered for use on vegetables in the United States, has shown promise as a soil nematicide on some crops (da Rocha et al. 2017) and would offer vegetable growers more management options if it becomes available.

Nonfumigant nematicides currently marketed in the United States for RKN management in vegetable systems are effective if used at labeled rates; however, caution needs to be taken to select a proper nematicide for use based on what level of $\mathrm{RKN}$ population is present in soil and how long the crop takes to mature. Under ideal soil temperature and moisture conditions, Meloidogyne spp. can complete one generation within 21 to 24 days (Moens et al. 2009). In this study, cucumber was grown for 60 days in outdoor conditions with an average temperature of 25.1 and $27.3^{\circ} \mathrm{C}$ in the first and repeat trial, respectively, which may have allowed the nematode to complete two generations. RKN can complete three to four generations on fruiting vegetables such as tomato, pepper, or eggplant, which require about 70 to 90 days to mature, resulting in higher nematode damage and lower crop yields. Because the effect of nonfumigant nematicides is restricted to a few weeks after planting (Colyer et al. 1997), selection of a proper nonfumigant nematicide is of great importance. When the use of a nematicide is necessary, the application of the most effective material will give producers the highest return on their input. However, this depends on the cost per hectare of the nematicides. If the most effective material is too expensive, then the highest return could be from a less effective but less expensive nematicide.

Generally, our trials revealed that both fluensulfone and fluazaindolizine were the most effective nematicides for $M$. incognita control in cucumber, and oxamyl was the least effective at the highest inoculation densities of the nematode. Although nematicides are useful in inhibiting RKN infection, yield reductions may still occur, particularly in soil with heavy RKN pressure. Results of this work give perceptions that should be considered for improving the efficiency of nonfumigant nematicides in the production of vegetable crops.

\section{Acknowledgments}

We thank B. H. Luke and K. Ray for technical assistance; and X. Luo for assistance with statistical analysis.

\section{Literature Cited}

Barker, K. R., Shoemaker, P. B., and Nelson, L. A. 1976. Relationships of initial population densities of Meloidogyne incognita and M. hapla to yield of tomato. J. Nematol. 8:232-239.
Brodie, B. B. 1971. Differential vertical movement of nonvolatile nematicides in soil. J. Nematol. 3:292-295.

Colyer, P. D., Kirkpatrick, T. L., Caldwell, W. D., and Vernon, P. R. 1997. Influence of nematicide application on the severity of the root-knot nematode-Fusarium wilt disease complex in cotton. Plant Dis. 81:66-70.

da Rocha, M. R., Teixiera, R. A., Cabral, W. C., Serikawa, R., Almeida, N. O., de Oliveira, C. M., and Freire, L. L. 2017. The efficacy of Salibro ${ }^{\mathrm{TM}}$ (fluazaindolizine) on Meloidogyne incognita in corn. Nematropica 47:8 (Abstr.)

Davis, R. F. 2007. Effect of Meloidogyne incognita on watermelon yield Nematropica 37:287-293.

Desaeger, J. A., and Csinos, A. S. 2006. Root-knot nematode management in double-cropped plasticulture vegetables. J. Nematol. 38:59-67.

Di Vito, N., Greco, N., and Carella, A. 1986. Effect of Meloidogyne incognita and importance of the inoculum on the yield of eggplant. J. Nematol. 18:487-490.

Glantz, S. A., and Slinker, B. K. 2001. Primer of Applied Regression and Analysis of Variance. 2nd ed. McGraw-Hill, Medical Pub. Division, New York, NY. Pages 25-28.

Gugino, B., Abawi, G. S., and Ludwig, J. W. 2006. Damage and management of Meloidogyne hapla using oxamyl on carrot in New York. J. Nematol. 38:483-490.

Hajihassani, A. 2018. Chemical Nematicides for Control of Plant-Parasitic Nematodes in Georgia Vegetable Crops.University of Georgia, College of Agriculture and Environmental Sciences Cooperative Extension Service. Bulletin 1502. https:// secure.caes.uga.edu/extension/publications/files/pdf/B\%201502 1.PDF.

Hajihassani, A., Lawrence, K., and Jagdale, G. B. 2018. Plant parasitic nematodes of Georgia and Alabama. Pages 357-391 in: Plant Parasitic Nematodes in Sustainable Agriculture of North America. S. A. Subbotin and J. Chitambar, eds. Springer, Switzerland.

Hajihassani, A., Rutter, W. B., and Luo, X. 2019. Resistant pepper carrying N, $M e 1$, and $M e 3$ have different effects on penetration and reproduction of four major Meloidogyne species. J. Nematol. 51:1-9.

Hussey, R. S., and Janssen, G. J. W. 2002. Root-knot nematode: Meloidogyne species. Pages 43-70 in: Plant Resistance to Parasitic Nematodes. J. L. Starr, R. Cook, and J. Bridge, eds. CAB International, Wallingford, UK.

Jenkins, W. R. 1964. A rapid centrifugal-flotation technique for separating nematodes from soil. Plant Dis. Rep. 48:692.

Johnson, A. W., Rohde, W. A., Dowler, C. C., Glaze, N. C., and Wright, W. C. 1981. Influence of water and soil temperature on the concentration and efficacy of phenamiphos on control of root-knot nematode. J. Nematol. 13:148-153.

Jones, J. G., Kleczewski, N. M., Desaeger, J., Meyer, S. L. F., and Johnson, G. C. 2017. Evaluation of nematicides for southern root-knot nematode management in lima bean. Crop Prot. 96:151-157.

Kimpinski, J., Arsenault, W. J., and Sturz, A. V. 2001. Differential effect of nematicide treatments on tuber yields in early- and late-maturing potato cultivars. Plant Pathol. 50:509-514.

Miller, H. N. 1971. Comparisons of three nematicides for the control of Meloidogyne incognita on gardenia. Plant Dis. Rep. 55:357-360.

Moens, M., Perry, R., and Starr, J. 2009. Meloidogyne species - a diverse group of novel and important plant parasites. Page 483 in: Root-knot Nematodes. R. N. Perry, M. Moens, and J. L. Starr, eds. CAB International, Wallingford, UK.

Morris, K. A., Langston, D. B., Davis, R. F., Noe, J. P., Dickson, D. W., and Timper, P. 2016. Efficacy of various application methods of fluensulfone for managing root-knot nematodes in vegetables. J. Nematol. 48:65-71.

Morris, K. A., Langston, D. B., Dickson, D. W., Davis, R. F., Timper, P., and Noe, J. P. 2015. Efficacy of fluensulfone in a tomato-cucumber double cropping system. J. Nematol. 47:310-315.

Oka, Y., Shukar, S., and Tkachi, N. 2012. Systemic nematicidal activity of fluensulfone against the root-knot nematode Meloidogyne incognita on pepper. Pest Manag. Sci. 68:268-275.

Oka, Y., Shuker, S., and Tkachi, N. 2013. Influence of soil environments on nematicidal activity of fluensulfone against Meloidogyne javanica. Pest Manag. Sci. 69:1225-1234.

Olthof, T. H. A., and Potter, J. W. 1972. The relationship between population densities of Meloidogyne hapla and crop losses in summer-maturing vegetables in Ontario. Phytopathology 62:981-986.

Proffer, T. J., Lizotte, E., Rothwell, N. L., and Sundin, G. W. 2013. Evaluation of dodine, fluopyram and penthiopyrad for the management of leaf spot and powdery mildew of tart cherry, and fungicide sensitivity screening of Michigan populations of Blumeriella jaapii. Pest Manag. Sci. 69:747-754.

Thies, J. A., Ariss, J. J., Kousik, C. S., Hassell, R. L., and Levi, A. 2016. Resistance to southern root-knot nematode (Meloidogyne incognita) in wild watermelon (Citrullus lanatus var. citroides). J. Nematol. 48:14-19.

Vrain, T. C., Belair, G., and Martel, P. 1979. Nonfumigant nematicides for control of root-knot nematode to protect carrot root growth in organic soils. J. Nematol. 11:328-333.

Walters, S. A., and Wehner, T. C. 2002. Incompatibility in diploid and tetraploid crosses of Cucumis sativus and Cucumis metuliferus. Euphytica 128: 371-374

Wolfe, K., and Stubbs, K. 2018. 2017 Georgia Farm Gate Value Report. Center for Agribusiness and Economic Development, University of Georgia, Athens, GA https://www.caes.uga.edu/content/caes-subsite/caed/publications/farm-gate.html

Zasada, I. A., Halbrendt, J. M., Kokalis-Burelle, N., LaMondia, J., McKenry, M. V., and Noling, J. W. 2010. Managing nematodes without methyl bromide. Annu. Rev. Phytopathol. 48:311-328. 